Helgoländer wiss. Meeresunters. 32, 425-435 (1979)

\title{
Structure and significance of cruciate flagellar root systems in green algae: Zoospores of Ulva lactuca (Ulvales, Chlorophyceae)
}

\author{
M. MelKonian \\ Botanisches Institut, Westfälische Wilhelms-Universität; \\ Schloßgarten 3, D-4400 Münster, Federal Republic of Germany
}

\begin{abstract}
The ultrastructure of the flagellar apparatus in the quadriflagellate zoospores of Ulva lactuca was examined. The two L-shaped pairs of basal bodies are arranged in mirror image relation. Two apical capping plates connect adjacent basal bodies of different pairs with each other. The flagellar root system is cruciate and exhibits a microtubular part (4-2-4-2 system) and a complex and elaborate fibrillar part. The latter consists of two striated fibres (striation pattern $32 \mathrm{~nm}$ ) closely associated with the two-stranded roots and four differently patterned fibres (striation pattern $150-160 \mathrm{~nm}$ ) which are more internally located and run parallel to all four microtubular roots. The presence of four microtubular roots and six striated fibres is at present not known for any other green alga and taxonomic implications are discussed.
\end{abstract}

\section{INTRODUCTION}

In the past few years ultrastructural studies of the green algae with special emphasis on mitosis/cytokinesis and motile cell structure have led to a reclassification of this group (for review see Pickett-Heaps, 1975; Stewart \& Mattox, 1975; Stewart \& Mattox, 1978). Although certain aspects of the fine structure of the Ulvales have been previously described (e. g. Bråten \& Løvlie, 1968; Bråten, 1971; Hori, 1973; Stewart et al., 1973; Mattox \& Stewart, 1974) including some information on motile cell structure (Evans \& Christie, 1970; Micalef \& Gayral, 1972; Mattox \& Stewart, 1973, Jonsson \& Chesnoy, 1974; Swanson \& Floyd, 1978) no detailed account has been made of the flagellar apparatus in any member of the Ulvales. Recently Moestrup (1978) described some aspects of the flagellar apparatus in Monostroma greville $i$ and showed that gametes exhibited a 4-2-4-2 cruciate flagellar root system, a system which is of widespread occurrence in the Chlorophyceae sensu Stewart \& Mattox (for review see Moestrup, 1978). On the other hand the cytokinetic system of the Ulvales lacks a phycoplast (Løvlie \& Bråten, 1970; Mattox \& Stewart, 1974; McArthur \& Moss, 1978), which is a characteristic feature of the Chlorophyceae sensu Stewart \& Mattox. The cytokinetic peculiarities together with the occurrence of scales on the surface of certain ulvalean swarmers (Jonsson \& Chesnoy, 1974; Mattox \& Stewart, 1973) have led to the tentative establishment of a third class of green algae, the Ulvaphyceae, besides the Chlorophyceae and Charophyceae (Stewart $\&$ 


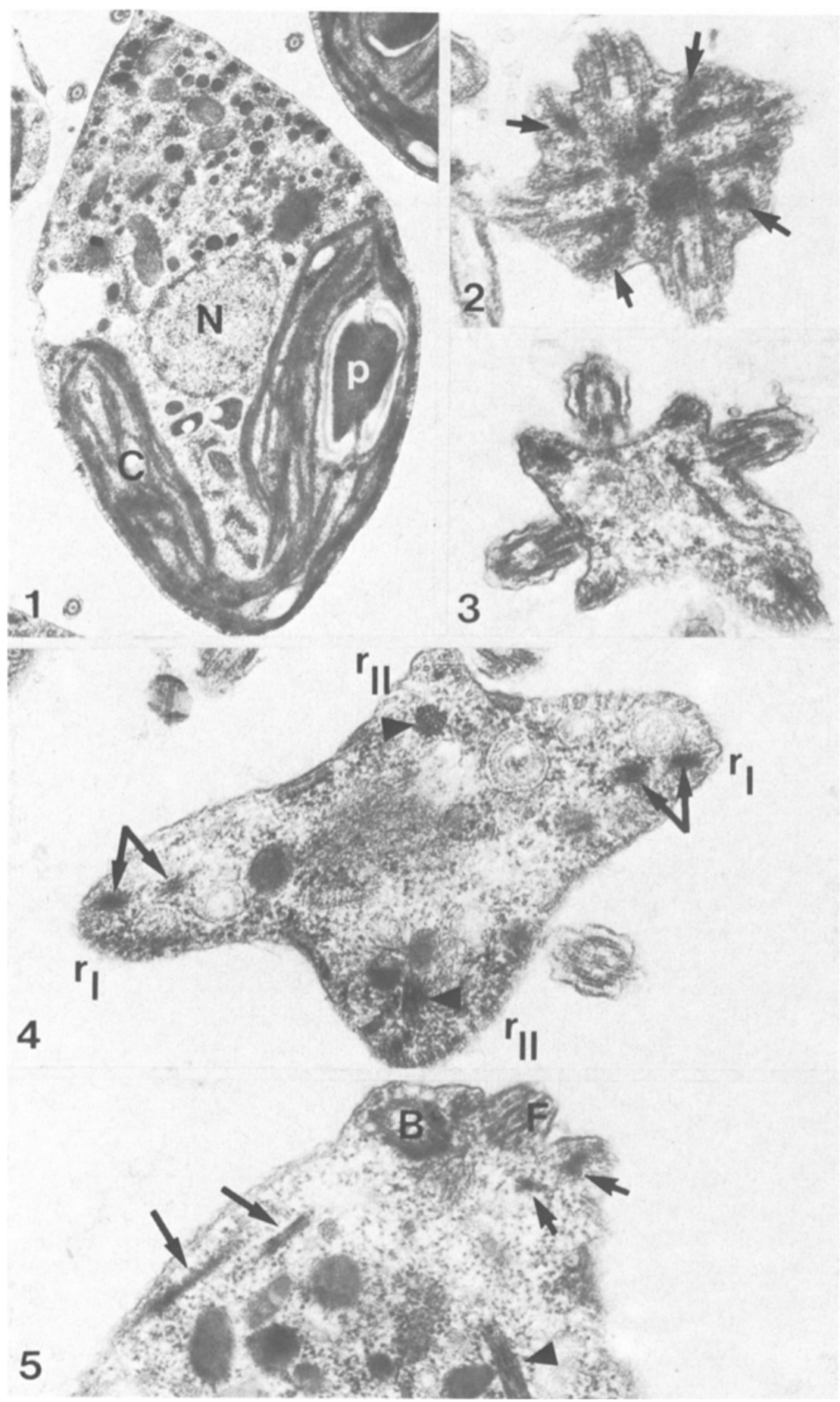


Mattox, 1978). A detailed analysis of the flagellar apparatus in the Ulvales was therefore greatly needed and this study was partly undertaken to fulfil such a requirement.

This study is the second part of a series on cruciate flagellar root systems in green algae (first contribution: Melkonian, 1978) which aims to evaluate structural variabilities and functional implications of cruciate root systems. Ulva lactuca was chosen for this purpose because reproductive stages with different numbers of flagella can be easily obtained (biflagellate gametes and quadriflagellate zoospores and zygotes) and peculiarities of the flagellar apparatus with respect to the bi- or quadriflagellate condition can be investigated. As a first step to this comparative approach the flagellar apparatus in quadriflagellate zoospores has been studied.

\section{MATERIALS AND METHODS}

Fertile thalli of Ulva lactuca L. were collected in the rocky flats at the West cliff of the island of Helgoland during spring tides in April 1977. Most of the fertile thalli were gametophytes. All fertile thalli were individually placed in plastic petri dishes in a moist but not wet condition. After return to the laboratory they were stored overnight in the petri dishes in a cool chamber $\left(10^{\circ} \mathrm{C}\right)$. The next morning the thalli were flooded with fresh seawater and placed at a northern light window. Within less than a minute large masses of reproductive cells were discharged. While gametes showed strong positive phototactic behaviour and accumulated at the meniscus near the light source, the zoospores were either not or slightly negative phototactic and tended to accumulate at the bottom of the petri dish at the site away from the light or below the thallus in the darkest region. Zoospores became immotile within minutes and fixation for electron microscopy was carried out during backward swimming of zoospores away from the light. Fixation was performed by mixing equal amounts of $2 \%$ glutaraldehyde made up in $0.25 \mathrm{M}$ saccharose without buffer but final $\mathrm{pH}$ adjustment to 8.2 with zoospore suspension in seawater, giving a final glutaraldehyde concentration of $1 \%$. The cells were fixed for $30 \mathrm{~min}$ at $20^{\circ} \mathrm{C}$. After centrifugation they were washed three times with seawater and postfixed in $1 \% \mathrm{OsO}_{4}$ (prepared as a $2 \%$ solution in $0.25 \mathrm{M}$ saccharose and mixed with equal amounts of

Fig. 1: A nearly median longitudinal section through a zoospore of Ulva lactuca. $\mathrm{N}=$ nucleus, $\mathrm{C}=$ chloroplast, $\mathrm{p}=$ pyrenoid. $(\mathrm{X} 8500$ )

Fig. 2: Transverse section through the apical part of the zoospore. $2 \mathrm{~L}$-shaped pairs of basal bodies and 4 flagellar roots (arrows) can be discerned. (X 39600 )

Fig. 3: A similar section as in Fig. 2 but slightly more posterior. The anterior end of the zoospore forms a cruciform papilla. (X 28 800)

Fig. 4: Transverse section through the anterior part of the cell with conspicuous cruciform papilla and some details of flagellar roots. Two types of roots can be distinguished $\left(r_{I}\right.$ and $\left.r_{I I}\right)$. Two electron-dense structures are associated with root type I (double arrows) and one prominent electron dense structure with root type II (triangles). Note secondary cytoskeletal microtubules associated with the flagellar roots. (X 36000$)$

Fig. 5: Oblique section through the anterior part of the cell. Different disposition of root associated fibres in both root types are shown (arrows and triangle). $\mathrm{B}=$ basal body, $\mathrm{F}=$ flagellum. (X 36000 ) 
seawater). Postfixation was carried out for $10 \mathrm{~min}$ at $4^{\circ} \mathrm{C}$. The fixed cells were again washed with seawater $\left(4^{\circ} \mathrm{C}\right)$ and stored in seawater for two days before further processing as previously described (Melkonian, 1975). Sections were examined with a Siemens Elmiskop 102.

\section{RESULTS}

The general ultrastructure of zoospores of Ulva has been previously described (Bråten \& Lovlie, 1968; Micalef \& Gayral, 1972). Figure 1 shows a micrograph of a nearly median longitudinal section through a zoospore of Ulva lactuca revealing organelle distribution.

The four basal bodies of the zoospore are arranged as two L-shaped pairs in mirror image relation as in some other quadriflagellate green cells (Fig. 2). The flagella emerge from gaps between four projecting ribs which form a cruciform papilla in transverse sections through apical parts of the cell (Fig. 3,4). Within these projecting ribs run the 4 flagellar roots, which are, therefore, alternating with the flagella and cruciately arranged.

The internal structure of the flagellum, the transitional region and the basal body do not reveal any new features; a stellate pattern in the transitional region and a cartwheel pattern in the basal body have been found. Of some significance however is an electrondense capping structure (here provisionally named "terminal cap") which closes the proximal end of a basal body, being attached to the inner part of the basal body triplets (Fig. 17). This cap is about $25 \mathrm{~nm}$ thick and only seen in median longitudinal sections through basal bodies.

Adjacent basal bodies of different basal body pairs are connected with each other through a special electron-dense capping plate (Fig. 10). The two capping plates touch each other and the existence of two plates can only be ascertained in favourable median longitudinal sections through opposite basal bodies. Opposite basal bodies and adjacent basal bodies of one basal body pair are not interconnected by a special fibre or plate, but a more indirect connection exists via the two touching capping plates. Furthermore basal bodies of one basal body pair are connected with their proximal ends (Fig. 6). The capping plates were not striated in any plane of section.

The flagellar root system is compound, containing microtubular and striated fibrillar parts. The microtubular root system consists of two root types, a two-stranded and a fourstranded root (4-2-4-2 system). Different aspects of these roots are depicted in the respective cross sections (Figs 6 13). The two-stranded root originates near one basal body in the space between one basal body pair (Fig. 6). The microtubules are surrounded by conspicuous electron-dense material. There is no obvious connection of root microtubules

Figs 6, 7, 8, 9: Cross sections through the two-stranded microtubular toot. Fig. 6: Proximal section indicating root tubules (straight arrow) near a basal body (B). One of the two capping plates is also seen (curved arrow). (X 50 000). Figs 7-9: Subsequently more distal cross sections through the twostranded root. Electron-dense material underlies the root tubules (Fig. 9, arrow). $\mathrm{cM}=$ secondary cytoskeletal microtubules. In Fig. 8 an arrow indicates electron dense material (striated fibre of 150-160 nm periodicity). Fig. 7: X 64 000; Fig. 8: X 72 000; Fig 9: X 72000

Figs 10-13: Different aspects of the four-stranded microtubular root in cross sections (root type II) 


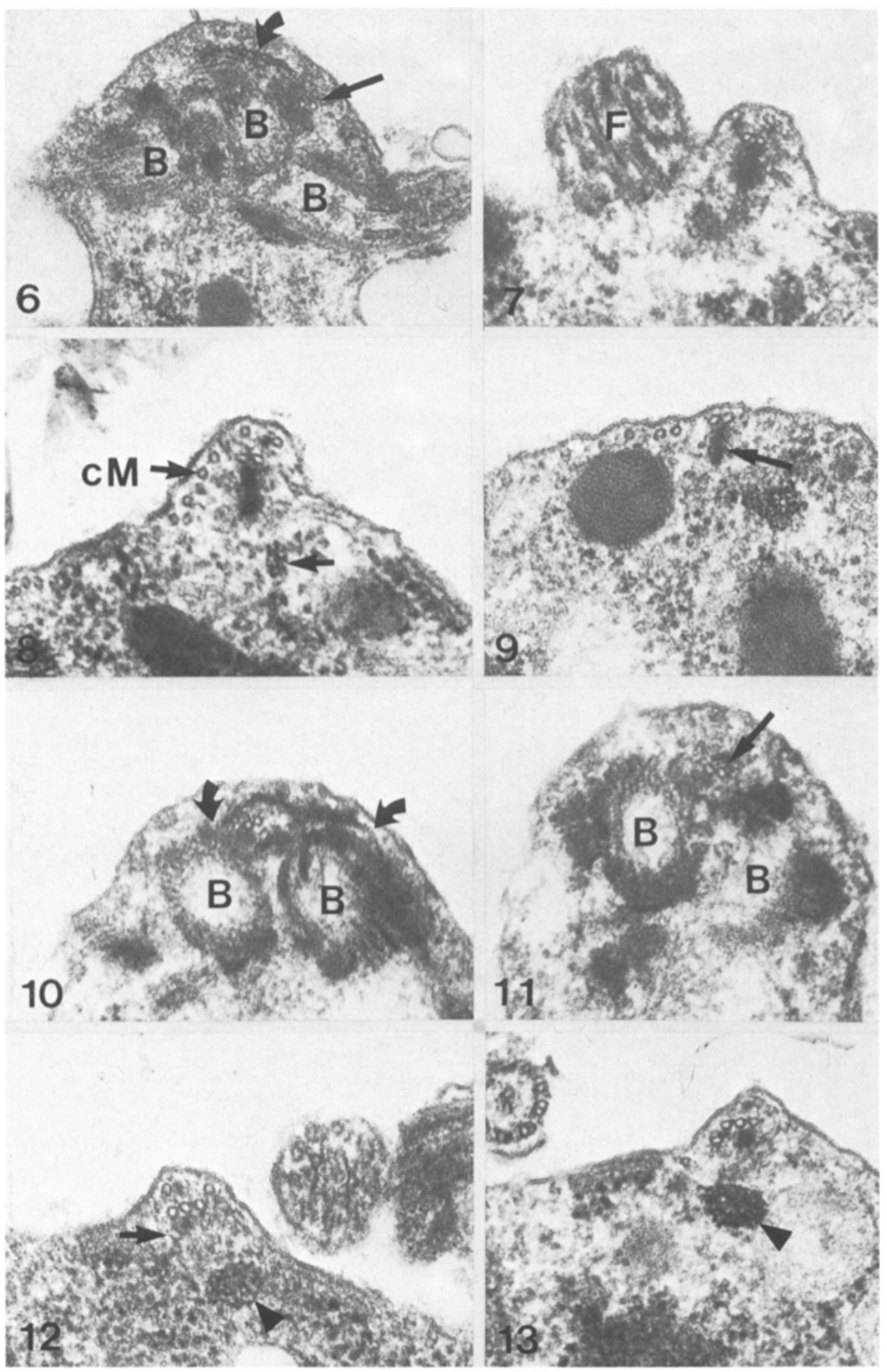


with the overlying capping plate (Fig. 6). In more distal cross sections (Figs, 7-9) the microtubules can be seen to be associated with underlying electron-dense material, which makes them easily recognizable even in sections some distance away from the basal bodies (Fig. 9). The other root type originates near a basal body in the space between basal bodies of different basal body pairs (Fig. 10). It consists of four microtubules along its length which display typical configurational changes. In the most proximal cross sections (Fig. 10) root tubules are arranged in a 3 over $1(3+1)$ pattern, with tubule 1 (nomenclature after Melkonian, 1978) located just below tubule 4. In this region tubules 2 and 3 are connected with capping plate by small links (Fig. 10). This root tubule configuration changes in more distal parts, when tubule 1 moves with respect to the other three tubules and underlies tubule 3 (Fig. 11) and tubule 2 (Fig. 12) respectively. In the most distal sections tubule 1 leaves the other three root tubules (Fig. 13).

In addition to the microtubular part of the flagellar root system zoospores of Ulva lactuca are characterized by a complex system of striated fibres (Figs 4, 5). One type of striated fibre is only associated with the two-stranded roots and is embedded in the underlying electron-dense material. This fibre is striated when sectioned longitudinally (Figs 15, 16, 17, 19,) and the repetitive unit out of ten different sections has been determined to be $32 \mathrm{~nm}$ and is apparently constant within one fibre and between different fibres. The cross banding pattern consists of two dark lines delimiting a light space (length about $9 \mathrm{~nm}$ ) and a broader dark space separating each set of dark lines (length about $23 \mathrm{~nm}$ ) (Fig. 19). Individual fibrils could not be distinguished in this type of fibre. The striated fibres of this type are maximally $1.5 \mu \mathrm{m}$ long, $30 \mathrm{~nm}$ wide and approximately $70-100 \mathrm{~nm}$ thick. The fibres terminate near the proximal end of a basal body (Fig. 17). In some proximal cross sections through the two-stranded root overlying electron-dense material

Fig. 10: Proximal cross section through this root type. Root tubules are arranged in a 3 over 1 configuration. One capping plate connects adjacent basal bodies (B) of different basal body pairs (curved arrows) X 63000

Figs 11, 12, 13: Subsequently more distal cross sections through this root type. Root tubule configuration gradually changes from a 3 over 1 (Fig. 11) to a 3 besides 1 (Figs. 12, 13). Tubule 1 changes its position with respect to the other three tubules (Fig. 12, arrow: tubule 1). Electron-dense material (striated fibre of $150-160 \mathrm{~nm}$ periodicity) underlies the root tubules at some distance more interior located (triangle). Fig. 11: X 76 000; Fig. 12: X 76 000; Fig. 13: X 63000

Figs 14, 15: Longitudinal sections along both root types, showing that one root is associated only with one fibre (Fig. 14, triangle), while the other root type is associated with two different fibres (Fig. 15). In Fig. 14 a two-stranded root is cross-sectioned near a flagellum (F) and overlying electron-dense material is visible (arrow). Fig. 14: X 60 000; Fig. 15: X 76000

Figs 16, 17: Different longitudinal sections through the fibre of $32 \mathrm{~nm}$ periodicity. Note secondary cytoskeletal microtubules in Fig. 16 and "terminal cap" in Fig. 17 (arrow) Fig. 16: X 75 000; Fig. 17: X 75000

Figs 18, 19: Higher magnification of both fibre types in longitudinal section

Fig. 18: The striated fibre of $150-160 \mathrm{~mm}$ periodicity. The repetitive unit is indicated by the two triangles. X 112500

Fig. 19: The striated fibre of $32 \mathrm{~nm}$ periodicity. The repetitive unit is indicated by the two arrows. $\mathrm{X} 165000$ 

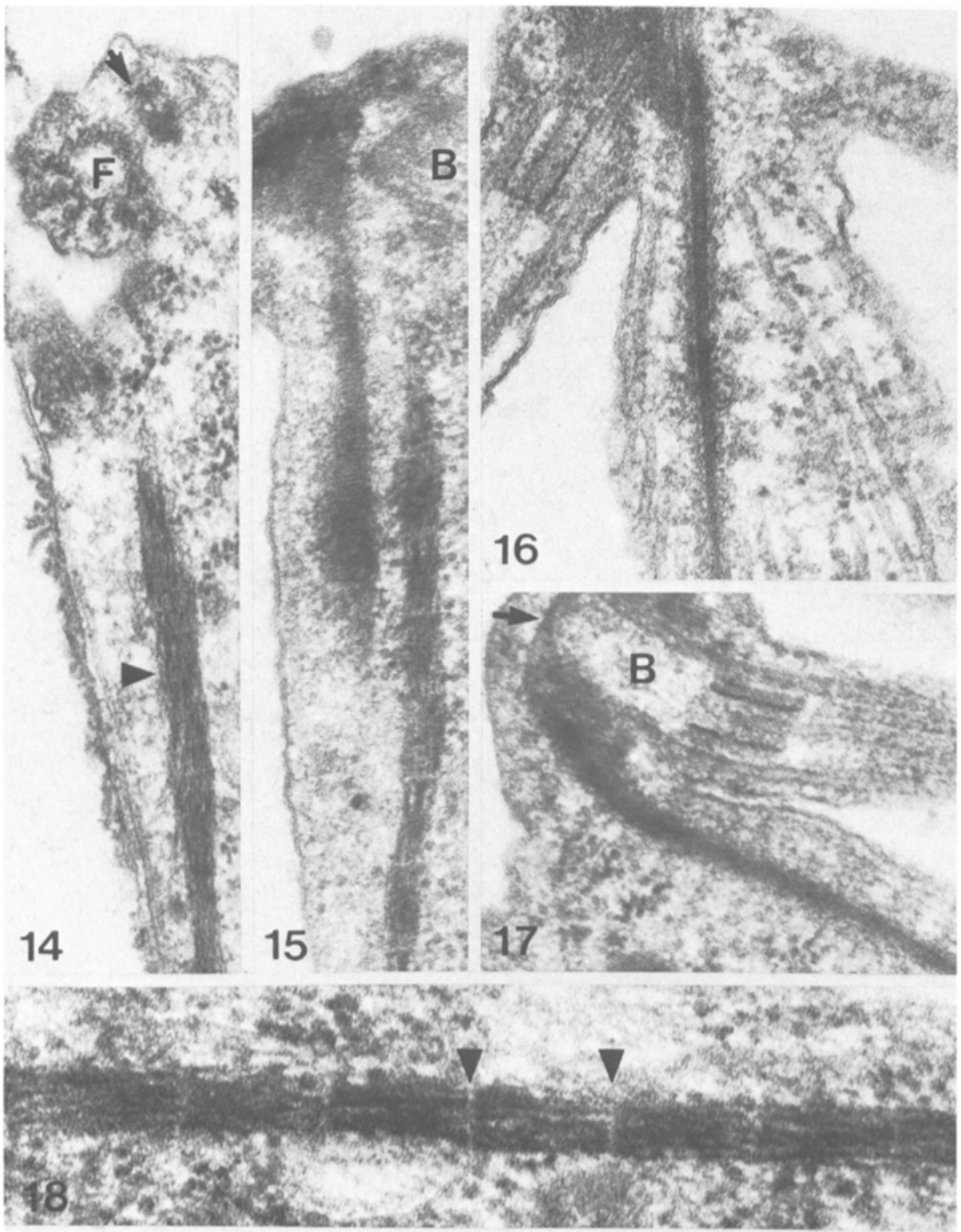

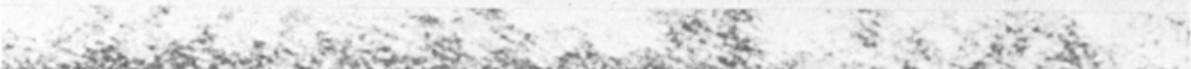

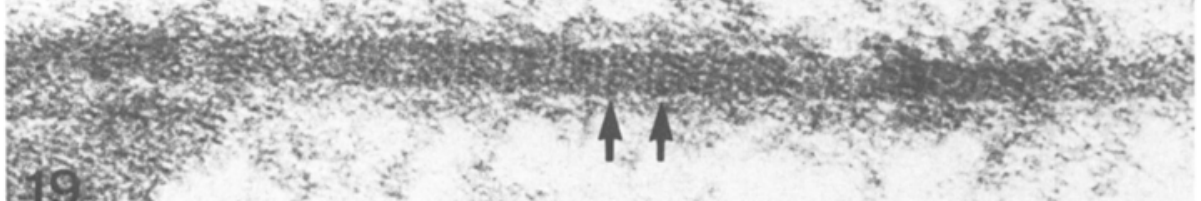


was also noticed (Fig. 14). Whether this represents another type of fibre is not known, but if so it is certainly much less elaborate than the underlying striated fibre.

The second type of striated fibre is associated with all four microtubular roots, but runs at some distance (about $150-200 \mathrm{~nm}$ ) parallel to the root microtubules and is more internally located (Figs 4, 5, 8, 12, 13). The four fibres are identical in substructure and consist of a varying number of thick fibrils (diameter $80 \AA$ ) interrupted by cross bars (Figs $15,18)$. The number of fibrils per fibre varied between 15 and 80 and usually the fibres associated with the two-stranded roots exhibited fewer fibrils than the other two fibres, although exceptions were also noted (e.g. Fig. 9). The repetitive unit varied between $150-160 \mathrm{~nm}$ and appeared to be fairly constant within a fibre and between different fibres. The striated fibres of this type are maximally $2.4 \mu \mathrm{m}$ long and they terminate in the midregion of the respective basal body on the side towards the cell proper. Therefore in proximal cross sections through microtubular roots this fibre is not seen (e. g. Figs 6, 10, 11). The distal termination of both fibre types has not been determined, but they remain in a superficial position and approach the plasmalemma.

Numerous (almost 100) secondary cytoskeletal microtubules were seen to be associated with the proximal parts of the 4 roots (Fig. 4 and cross sections Figs 8,9).

\section{DISCUSSION}

In the Ulvales some information on the flagellar apparatus of reproductive cells in the following genera is available: Ulva lactuca (Micalef \& Gayral, 1972), Monostroma grevillei (Jonsson \& Chesnoy, 1974; Moestrup, 1978), Enteromorpha intestinalis (Evans \& Christie, 1970), Trichosarcina polymorpha (Mattox \& Stewart, 1973) and Blidingia minima (Swanson \& Floyd, 1978). These studies have indicated that the motile cells of the Ulvales are characterized by a cruciate flagellar root system. Only in Monostroma grevillei (Moestrup, 1978) have the microtubular roots been studied more closely and the presence of a 4-2-4-2 cruciate root system been documented. In addition to the microtubular roots Micalef \& Gayral (1972) have demonstrated the presence of two types of striated fibres associated with the two-stranded root in zoospores of Ulva lactuca, which they termed system I and system II. A system II fibre (periodicity $150 \mathrm{~nm}$ ) has also been visualized in gametes of Monostroma grevillei (Jonsson \& Chesnoy, 1974) and zoospores of Enteromorpha intestinalis (Evans \& Christie, 1970).

This study on zoospores of Ulva lactuca has extended the observations of Micalef \& Gayral (1972) in several ways: A 4-2-4-2 cruciate microtubular root system was found and in addition 6 striated fibres of two types were observed. One type (periodicity $32 \mathrm{~nm}$ ) was closely associated with the two-stranded roots, while the other (4 fibres; system II in the terminology of Micalef \& Gayral, 1972) was arranged parallel to all four microtubular roots. Such a complex flagellar root system has so far not been found in the green algae, but it is suggested that careful studies might reveal a more general occurrence of this type of root system in the Ulvales.

A 4-2-4-2 cruciate microtubular root system is of widespread occurrence in the Chlorophyceae sensu Stewart \& Mattox and the Prasinophyceae sensu Christensen (Moestrup, 1978; Melkonian, 1979). Moestrup (1978) has suggested that the primitive 
condition of a cruciate flagellar root system was an $\mathrm{X}-2-\mathrm{X}-2$ type. The universal occurrence of such systems in the green algae might further be indicative of some common important function of these systems, which is, however, at present unknown (for discussion of some functional aspects see Melkonian, 1978). On the other hand it is now quite certain that variations in root tubule numbers cannot be used for taxonomic purposes above the level of the genus, because variations sometimes occur within a strain or between different species of a single genus (Moestrup, 1978; Melkonian, 1978). In the light of this situation algae with equally numbered cruciate root systems (Urospora: Kristiansen, 1974; Carteria: Lembi, 1975; Schizomeris: Birkbeck et al., 1974) appear to be quite distinct from algae posessing the X-2-X-2 type of root system. It is however suggested that these algae should be reinvestigated using serial sections and methods to distinguish between root microtubules and secondary cytoskeletal microtubules, because the latter especially in quadriflagellate cells seem to be organized at electron-dense material adjacent to root microtubules (e. g. Brown et al., 1976) and can be mistaken for root microtubules. Since the two types of microtubules show different sensitivity to cold and microtubule inhibitors (Melkonian et al., in preparation) a reevaluation might be profitable.

The apical capping plates and the "terminal caps" have not been hitherto found in other green algae. Similar but not identical structures were observed in gametes of Bryopsis (Hori, 1977 and own observations) and in zoospores of Microthamnion (Watson, 1975).

The two striated fibres associated with two-stranded roots might be of more general occurrence in the green algae than previously thought. They seem to be identical in substructure, repetitive unit and location (below the two root microtubules) to the fibres described in zoospores of the Chaetophorales Stigeoclonium (Manton, 1964) and Fritschiella (Melkonian, 1975), while in biflagellate motile cells similar but not identical fibres are situated above the two root microtubules at present described only for Cblamydomonas (Goodenough \& Weiss, 1978) and Chlorosarcinopsis (Melkonian, 1978). Whether a fibre located above the root microtubules is present in Ulva zoospores remains to be investigated, perhaps using the negative staining technique with isolated flagellar root systems. With this technique Hyams \& Chasey (1974) have shown the presence of 4 very short striated fibres (periodicity $25-30 \mathrm{~nm}$ ) associated with the four microtubular roots in Dunaliella. The only quadriflagellate organism in which striated fibres overlying twostranded roots were found is Polytomella (Brown et al., 1976).

The other four striated fibres with a repetitive unit of $150-160 \mathrm{~nm}$ occurring in Ulva lactuca zoospores in their substructure resemble rhizoplasts. Rhizoplasts are, however, usually located more towards the interior and approach the nucleus. They have up to now only been found in a few green algae (summarized by Robenek \& Melkonian, in press). In this respect it is quite interesting that in zoospores of the marine green alga Urospora penicilliformis 4 striated fibres of similar periodicity to that in Ulva were found, but which run from the basal bodies to the nucleus. To what extent these fibres relate to the striated fibres of Ulva remains an open question. The function of both fibre types in Ulva lactuca zoospores is also not known, but preliminary observations indicate that they are associated with the mating type structure of gametes of Ulva and may play a role in gametic fusion (Melkonian, in preparation).

In conclusion, it can be stated that Ulva lactuca zoospores exhibit a cruciate flagellar root system, of which the microtubular part (4-2-4-2) is of widespread occurrence in the 
green algae, while the fibrillar part (6 striated fibres of two types) is at present not known in other green algae. Only when more ulvalean algae are investigated with respect to the flagellar apparatus can the significance of these peculiarities become more clear.

Acknowledgements. Part of the study has been made at the Biologische Anstalt Helgoland and I would like to thank the Director for giving me the opportunity to use the facilities of the Biologische Anstalt as a guest during several weeks in 1976 and 1977. Special thanks are due to Dr. Dr. h. c. P. Kornmann and Dr. K. Lüning (Helgoland) for their advice and interest in the study and to Mrs. B. Surek for help in collecting the algae. Mrs. I. Wachholz, Mrs. B. Berns and Mrs. S. Tschauner have helped during various stages of the work.

\section{LITERATURE CITED}

Birkbeck, T. E., Stewart, K. D. \& Mattox, K. R., 1974. The cytology and classification of Schizomeris leibleinii (Chlorophyceae). II. The structure of quadriflagellate zoospores. Phycologia 13, 71-79.

Bråten, T., 1971. The ultrastructure of fertilization and zygote formation in the green alga Ulva mutabilis Føyn. J. Cell Sci. 9, 612-635.

- \& Løvlie, A., 1968. On the ultrastructure of vegetative and sporulating cells of the multicellular green alga Ulva mutabilis Føyn. Nytt Mag. Bot. 15, 209-219.

Brown, D. L., Massalski, A., \& Patenaude, R., 1976. Organization of the flagellar apparatus and associated cytoplasmic microtubules in the quadriflagellate alga Polytomella agilis. J. Cell Biol. 69, 106-125.

Evans, L. V., \& Christie, A. O., 1970. Studies on the ship-fouling alga Enteromorpha. I. Aspects of the fine structure and biochemistry of swimming and newly settled zoospores. Ann.Bot 34, 451-456.

Goodenough, U. W., \& Weiss, R. L., 1978. Interrelationships between microtubules, a striated fiber, and the gametic mating structure of Chlamydomonas reinhardi. J. Cell Biol. 76, 430-438.

Hori, T., 1973. Comparative studies of pyrenoid ultrastructure in algae of the Monostroma complex. J. Phycol. 9, 190-198.

- 1977. Electron microscope observations on the flagellar apparatus of Bryopsis maxima (Chlorophyceae). J. Phycol. 13, 238-243.

Hyams, J., \& Chasey, D., 1974. Aspects of the flagellar apparatus and associated microtubules in a marine alga. Expl Cell Res. 84, 381-387.

Jonsson, S., \& Chesnoy, L, 1974. Etude ultrastructurale de l'incorporation des axonemes flagellaires dans les zygotes du Monostroma grevillei (Thuret) Wittr., Chlorophyceae marine. C. r. hebd. Séanc. Acad. Sci. Paris (D), 278, 1557-1560.

Kristiansen, J., 1974. The fine structure of the zoospores of Urospora penicilliformis with special reference to the flagellar apparatus. Br. phycol. J. 9, 201-213.

Lembi, C. A., 1975. The fine structure of the flagellar apparatus of Carteria. J. Phycol. 11, 1-9.

Løvlie, A., \& Bråten, T., 1970. On mitosis in the multicellular alga Ulva mutabilis. J. Cell Sci. 6, 109-129.

Manton, I., 1964. Observations on the fine structure of the zoospore and young germling of Stigeodonium. J. exp. Bot. 15, 399-411.

Mattox, K. R., \& Stewart, K. D., 1973. Observations on the zoospores of Pseudendoclonium basiliense and Trichosarcina polymorpha (Chlorophyceae). Can. J. Bot. 51, 1425-1430.

- \& Stewart, K. D., 1974. A comparative study of cell division in Pseudendoclonium basiliense and Trichosarcina polymorpha (Chlorophyceae). J. Phycol. 10, 447-456.

McArthur, D. M., \& Moss, B. L., 1978. Ultrastructural studies of vegetative cells, mitosis and cell division in Enteromorpha intestinalis (L.) Link. Br. phycol. J. 13, 255-267.

Melkonian, M., 1975. The fine structure of the zoospores of Fritschiella tuberosa Iyeng. (Chaetophorineae, Chlorophyceae) with special reference to the flagellar apparatus. Protoplasma 86, 391-404.

- 1978. Structure and significance of cruciate flagellar root systems in green algae: Comparative investigations in species of Chlorosarcinopsis (Chlorosarcinales). Pl. Syst. Evol. 130, 265-292. 
- 1979. An ultrastructural study of the flagellate Tetraselmis cordiformis Stein (Chlorophyceae) with emphasis on the flagellar apparatus. Protoplasma 98, 139-151.

Micalef, H., \& Gayral, P., 1972. Quelques aspects de l'infrastructure des cellules vegetatives et des cellules reproductrices d'Ulva lactuca L. (Chlorophycees). J. Microsc. 13, 417-428.

Moestrup, Ø., 1978. On the phylogenetic validity of the flagellar apparatus in green algae and other chlorophyll a and b containing plants. Bio Systems 10, 117-144.

Pickett-Heaps, J. D., 1975. Green algae. Sinauer, Sunderland, Mass. 606 pp.

Robenek, $\mathrm{H}$., \& Melkonian, M., Rhizoplast-membrane associations in the flagellate Tetraselmis cordiformis Stein (Chlorophyceae) revealed by freeze-etching and thin sections. Arch. Protistenk. (in press)

Stewart, K. D., Mattox, K. R., \& Floyd, G. L., 1973. Mitosis, cytokinesis, the distribution of plasmodesmata and other cytological characteristics in the Ulotrichales, Ulvales and Chaetophorales: Phylogenetic and taxonomic considerations. J. Phycol. 9, 128-141.

- - 1975. Comparative cytology, evolution and classification of the green algae with some consideration of the origin of other organisms with chlorophyll a and b. Bot. Rev. 41, 104-135.

- 1978 . Structural evolution in the flagellated cells of green algae and land plants. Bio Systems 10, 145-152.

Swanson, J. A., \& Floyd, G. L., 1978. Fine structure of the zoospores and thallus of Blidingia minima. Trans. Am. microsc. Soc. 97, 549-558.

Watson, M. W.,1975. Flagellar apparatus, eyespot and behavior of Microthamnion kuetzingianum (Chlorophyceae) zoospores. J. Phycol. 11, 439-448. 